\title{
Role of Platelet Cytoskeleton in Platelet Biomechanics: Current and Emerging Methodologies and Their Potential Relevance for the Investigation of Inherited Platelet Disorders
}

\author{
Carlo Zaninetti ${ }^{1,2,3}$ Laura Sachs ${ }^{1}$ Raghavendra Palankar ${ }^{1}$ \\ 1 Department of Transfusion Medicine, Institute of Immunology and \\ Transfusion Medicine, University Medicine Greifswald, Greifswald, \\ Germany \\ 2 Department of Internal Medicine, University of Pavia and IRCCS \\ Policlinico San Matteo Foundation, Pavia, Italy \\ Address for correspondence Raghavendra Palankar, PhD, \\ Department of Transfusion Medicine, Institute of Immunology and \\ Transfusion Medicine Greifswald, University Medicine, Greifswald, \\ 17489 Greifswald, Germany \\ (e-mail: raghavendra.palankar@med.uni-greifswald.de).
}

3 PhD Course of Experimental Medicine, University of Pavia, Pavia, Italy

Hämostaseologie 2020;40:337-347.

\begin{abstract}
Keywords

- inherited platelet disorders

- cytoskeleton

- biomechanics

- imaging

Cytoskeleton is composed of more than 100 proteins and represents a dynamic network of the cellular cytoplasm. Cytoskeletal functions include spatial organization of cellular components, structural connection of the cell with external environment, and biomechanical force generation. Cytoskeleton takes part, at different levels, in all phases of platelet biogenesis: megakaryocyte (MK) differentiation, MK maturation, and platelet formation. In addition, it also plays a major role in each stage of platelet function. Inherited platelet disorders (IPDs) are a group of rare diseases featured by low platelet count and/or impaired platelet function. Over the past decade, the investigation of platelet biomechanics has become a major and highly relevant theme of research due to its implications at every stage of development of human life. The initial use of diverse biophysical techniques (e.g., micropipette aspiration, atomic force and scanning ion conductance microscopy, real-time deformability cytometry) started unraveling biomechanical features of platelets that are expected to provide new explanations for physiological and pathological mechanisms. Although the impact of cytoskeletal alterations has been largely elucidated in various IPDs' pathogenesis, the understanding of their impact on biomechanical properties of platelets represents an unmet need. Regarding IPDs, improving biomechanical studies seems promising for diagnostic and prognostic implications. Potentially, these characteristics of platelets may also be used for the prediction of bleeding risk. This review addresses the current available methods for biophysical investigations of platelets and the possible implementations in the field of IPDs.
\end{abstract}

\section{Introduction}

\section{Cytoskeleton in Human Cells}

Cytoskeleton is a dynamic network within the cellular cytoplasm composed of more than 100 constitutive and regulatory proteins. ${ }^{1}$ The main classes of cytoskeletal polymers are micro- tubules, representing the stiffest component, actin cytoskeleton, and the intermediate filaments. Microtubules and actin filaments are polarized proteins that facilitate movement of molecular motors such as myosin or dynein. Intermediate filaments, such as keratin and vimentin, interact with actin received

February 12, 2020

accepted after revision

May 11, 2020 (c) 2020 Georg Thieme Verlag KG Stuttgart · New York
DOI https://doi.org/

$10.1055 / \mathrm{a}-1175-6783$. ISSN 0720-9355. 
cytoskeleton and microtubules forming structures that support cells to resist and respond to tensile forces or shear stress. $^{2-4}$ The three principal functions of the cytoskeleton are (1) the spatial organization and trafficking of cellular contents, (2) the connection of the cell with the external environment at physical and biochemical levels, and (3) mechanotransduction and generation of biomechanical forces allowing the cell to move and modify its shape in response to stimuli. Thus, cytoskeleton plays a critical role in several key physiological and pathological processes, such as cell-shape maintenance, cell division, cell proliferation and migration, and tumor growth and progression. Our knowledge of cytoskeletal function at a molecular level is rapidly evolving, making its components even more precise disease biomarkers and possible therapeutic drug targets. ${ }^{2,5-7}$

Specific alterations in cytoskeletal elements, or proteins connecting the cytoskeleton to the cell membrane, are responsible for diseases affecting different systems. For instance, in hereditary spherocytosis, mutations of spectrin and ankyrin hinder the biconcave shape maintenance of the red blood cells. ${ }^{8}$ Besides, anomalies of the intermediate filament nuclear lamin $A / C$ represent the driving alterations of some genetic forms of dilated cardiomyopathy and muscular dystrophy. 9,10

\section{Cytoskeleton in Platelets}

Regarding cytoskeletal elements and their function/dysfunction, platelets share many similarities with other human cells but also several specificities. Cytoskeleton plays a major role both in platelet biogenesis and platelet function. ${ }^{11-14}$ Mature platelets derive from bone marrow megakaryocytes (MKs), which release them in the blood stream at the end of a complex process driven by thrombopoietin. ${ }^{15}$ Throughout their maturation process, MKs undergo polyploidization by switching from mitosis to endomitosis while cytokinesis is inhibited. Soon after, MKs form large membrane reservoirs and eventually elongate proplatelets into the sinusoids of the vascular niche of the bone marrow. ${ }^{16}$ Platelet formation and shaping continues within the blood flow, passing through the intermediate form of "preplatelets." Each of these processes is finely regulated at the cytoskeletal level, particularly through the modulation of the cleavage furrow and the tuning of the structure of $\beta 1$ tubulin. ${ }^{12,17}$ Before proplatelets are released from MKs, microtubules reassemble to transport granules and organelles from the MK cell body to the forthcoming proplatelet tips. ${ }^{18}$ Not surprisingly, the cytoskeletal machinery also contributes to the final platelet dimension. ${ }^{19,20}$

Although platelets participate in various processes beyond hemostasis, such as inflammation, innate immune response against bacterial pathogens, and interaction with tumor cells during cancer metastasis, their principal role is to safeguard vascular integrity. ${ }^{11,21-26}$ After adhesion to the damaged endothelium, integrin-dependent activation induces morphologic changes in platelets, which turn their original discoid shape to round to the peculiar "fried-egg" conformation. ${ }^{27,28}$ This process results in stronger plateletextracellular matrix (ECM) adhesion, followed by platelet aggregation and eventually platelet contraction. The cytoskeletal framework takes part in all the aforementioned steps, at different levels (-Fig. 1).

Immediately upon exposure of subendothelial ECM proteins in a damaged vessel, low-affinity binding between platelet GP Ib-IX-V complex and von Willebrand Factor is established under shear. The consequential activation of this receptor complex, alongside that of $G$ protein-coupled receptors, promotes a cytoskeleton-dependent rapid morphologic and functional transition of platelet integrins. Particularly GP IIb/IIIa, the most abundant platelet integrin, changes the conformation of its extracellular $\beta 3$ domain, thus increasing the affinity toward fibrinogen, fibronectin, and von Willebrand Factor. As a result, a stronger platelet adhesion to extracellular ligands via integrins is achieved. ${ }^{29-33}$

Cytoskeleton is at the crossroads of this process as it directly supports the adhesion-mediated morphological changes of integrins; at the same time, it senses the activated state of integrins and reacts by remodeling its structure to form filopodia and pseudopodia and initiates platelet contraction (-Fig. 2). The structural connectors between actin cytoskeleton and intracellular portions of integrins (e.g., $\beta$

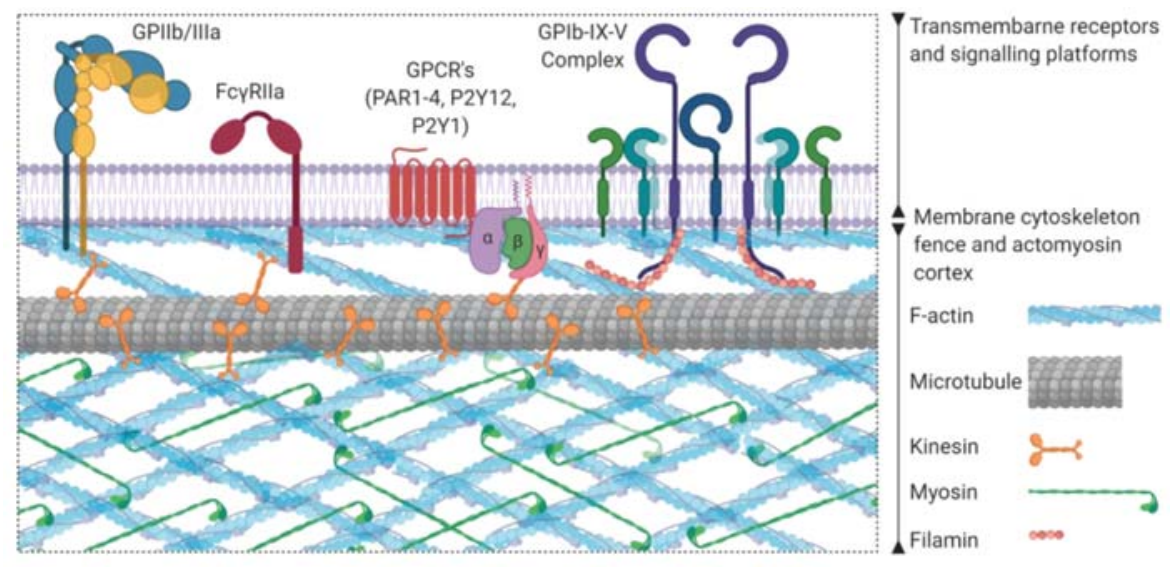

Fig. 1 Schematic representation of subcortical cytoskeletal framework in platelets. The main structural components of the platelet cytoskeleton (e.g., actin filaments, microtubules, a motor protein such as kinesin, an actin-binding protein such as filamin) are depicted. Moreover, the structural link between cytoskeletal elements and transmembrane receptors (e.g., GP Ib-IX-V complex, G-protein-coupled receptors, GPCRs, FcyRIla, and integrin GP IIb/IIla) is schematically illustrated. 

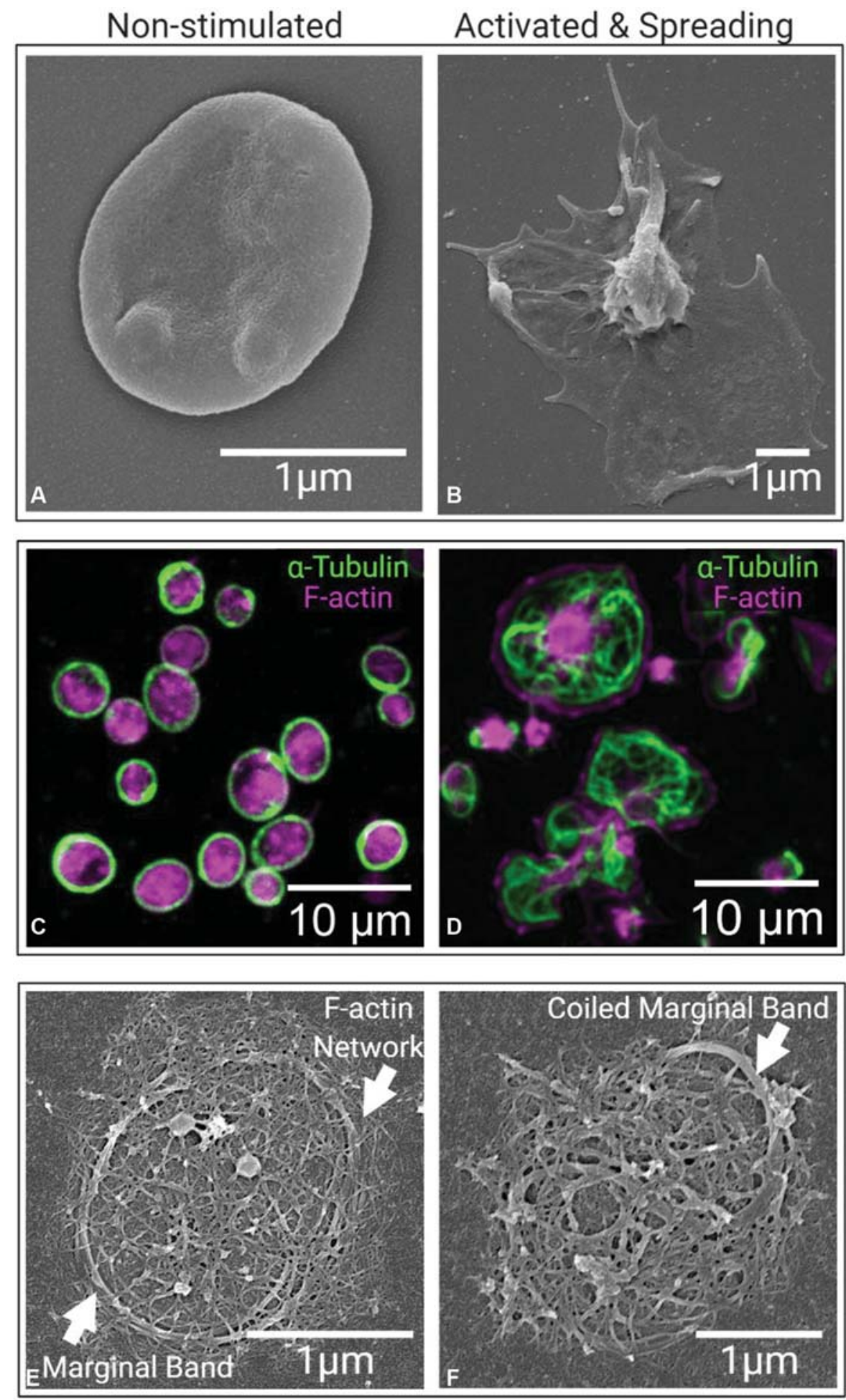

Fig. 2 Cytoskeletal remodeling upon platelet activation and spreading. (A, B) Rapid morphological changes occur in platelets from the resting to the activated state involving adhesion and spreading on a planar adhesive substrate, visualized by scanning electron microscopy. (C-F) Remodeling of marginal tubulin band (green) and actin (magenta) is assessed by immunofluorescence microscopy (C, D) and transmission electron microscopy after removing of platelet membrane (E, F).

tail of GP IIb/IIla) are diverse proteins such as filamin, myosin, and actinin- $\alpha-1.14,34$

Moreover, upon platelet activation, cytoskeleton microtubules disassemble, which maintains the discoid platelet shape in nonactivated platelets, and actin filaments assemble. ${ }^{35-37}$ Actin-myosin interactions, supported by the microtubule architecture, drive platelet centripetal contraction and ensure the maintenance of platelet structure during spreading. ${ }^{38-40}$ Actin cytoskeleton also regulates the centralization of platelet organelles and the secretion of $\alpha$ - and dense granules..$^{41}$ Finally, cytoskeleton-generated contractile forces are crucial during the late hemostatic phase of clot contraction. ${ }^{39,42}$ 


\section{Techniques for Biophysical Assessment of Platelet Biomechanics}

Biomechanical properties of platelets, which are mainly contributed by the cytoskeleton, are increasingly recognized as highly relevant for platelet function. ${ }^{34,43}$ Alterations in biomechanical properties resulting in changes in contractility during adhesion-mediated spreading and intrinsic viscoelastic properties governing platelet deformation can potentially serve as label-free diagnostic markers of a pathophysiological state of blood platelets. ${ }^{44,45}$ A wide variety of biophysical techniques are currently used to assess cytoskeleton-dependent contractile force generation at piconewton $(\mathrm{pN})$ and biomechanical properties of platelets at nanometer $(\mathrm{nm})$ regimes. ${ }^{46-49}$ In this review we are focusing on micropipette aspiration, atomic force microscopy (AFM), scanning ion conductance microscopy (SICM), and real-time deformability cytometry (RT-DC) that offer varying degree of sensitivities and throughputs to investigate platelet biomechanics up to single platelets ( - Table 1 ).

\section{Micropipette Aspiration}

Micropipette aspiration is one of the earliest biophysical approaches that were adopted for characterization of biomechanical properties of single platelets. It relies on the quantification of membrane deformation exerted by suction pressure applied through a borosilicate glass micropipette while the induced surface deformation is continuously recorded in real-time by video microscopy. ${ }^{50}$ In the field of platelets, White et al performed some of the earliest known biophysical measurements on single-platelet biomechanics and assessed the effect of microtubules and actin filaments on platelet deformation. ${ }^{51}$ From the perspective of clinical relevance, investigation of platelets from patients affected with Bernard-Soulier syndrome (BSS) provided interesting insights into the relations between platelet sizes and their capability to undergo deformation. ${ }^{52}$

In addition, micropipette aspiration has been applied to evaluate the biomechanical changes induced by platelet agonists such as thrombin and ADP as well as antiplatelet drugs such as acetylsalicylic acid. ${ }^{53,54}$

\section{Atomic Force Microscopy}

AFM is capable of providing a three-dimensional view of samples at nanometer $(\mathrm{nm})$ scale and to investigate intermolecular and/or intercellular forces in the region of sub-pN. The main structural component is a long silicon nitride cantilever with a sharp tip at one end that is scanned over the sample on the $x$-, $y$-, and $z$-axis. It can be used both to scan the sample providing information about the size according to cantilever deflection, and to test its rigidity by applying force. ${ }^{55}$ However, application of AFM to investigate platelets is a time-consuming and low-throughput technique and requires platelet immobilization. Despite these limitations, major findings on platelet biomechanics have been

Table 1 Comparison of biophysical techniques for assessment of platelet biomechanics

\begin{tabular}{|c|c|c|c|c|}
\hline Technique & Working principle & $\begin{array}{l}\text { Main potential applications } \\
\text { (in platelet field) }\end{array}$ & Major advantages & Limitations \\
\hline $\begin{array}{l}\text { Micropipette } \\
\text { aspiration }\end{array}$ & $\begin{array}{l}\text { Evaluation of membrane de- } \\
\text { formation exerted by suction } \\
\text { pressure through a borosili- } \\
\text { cate glass micropipette; the } \\
\text { induced surface deformation } \\
\text { is quantified by video } \\
\text { microscopy. }\end{array}$ & $\begin{array}{l}\text { To quantify viscoelastic } \\
\text { properties of single platelets } \\
\text { at baseline and/or induced by } \\
\text { soluble substances (e.g., } \\
\text { platelet agonists or cyto- } \\
\text { skeleton-destabilizing drugs) }\end{array}$ & $\begin{array}{l}\text { - Label-free } \\
\text { - Possibility of investiga- } \\
\text { tion at single-cell level }\end{array}$ & $\begin{array}{l}\text { - Low-throughput } \\
\text { - Technically highly de- } \\
\text { manding } \\
\text { - Time consuming } \\
\text { - Requires platelet } \\
\text { immobilization }\end{array}$ \\
\hline $\begin{array}{l}\text { AFM/colloidal } \\
\text { probe } \\
\text { spectroscopy }\end{array}$ & $\begin{array}{l}\text { Scanning of the sample } \\
\text { along three axes by a silicon } \\
\text { nitride cantilever that pro- } \\
\text { vides information about size } \\
\text { and rigidity according to } \\
\text { cantilever deflection and/or } \\
\text { pressing force application. }\end{array}$ & $\begin{array}{l}\text { - To evaluate platelet } \\
\text { elasticity at baseline and } \\
\text { upon adhesion to di- } \\
\text { verse substrates } \\
\text { - To characterize bio- } \\
\text { mechanical properties } \\
\text { of platelet aggregates } \\
\text { on various adhesive ma- } \\
\text { trixes and under differ- } \\
\text { ent shear-stress } \\
\text { conditions }\end{array}$ & $\begin{array}{l}\text { - Label-free } \\
\text { - Capacity of providing a } \\
\text { 3D view of samples at } \\
\text { nanometer scale } \\
\text { - Possibility of investiga- } \\
\text { tion of forces at inter- } \\
\text { cellular and } \\
\text { intermolecular levels in } \\
\text { the region of sub-pico- } \\
\text { newton } \\
\text { - Commercially available }\end{array}$ & $\begin{array}{l}\text { - Low throughput } \\
\text { - Technically highly de- } \\
\text { manding } \\
\text { - Time consuming } \\
\text { - Requires platelet } \\
\text { immobilization }\end{array}$ \\
\hline SICM & $\begin{array}{l}\text { Analysis of the sample by } \\
\text { assessing ionic current per- } \\
\text { turbation induced by the } \\
\text { specimen's features in re- } \\
\text { sponse to hydrostatic pres- } \\
\text { sure application. }\end{array}$ & $\begin{array}{l}\text { - To assess elasticity var- } \\
\text { iations upon platelet } \\
\text { spreading } \\
\text { - To correlate cytoskeletal } \\
\text { remodeling with stiff- } \\
\text { ness variations upon } \\
\text { platelet activation }\end{array}$ & $\begin{array}{l}\text { - Label-free } \\
\text { - High resolution } \\
\text { - Commercially available }\end{array}$ & $\begin{array}{l}\text { - Low throughput } \\
\text { - Technically demanding } \\
\text { - Time consuming } \\
\text { - Requires platelet } \\
\text { immobilization }\end{array}$ \\
\hline RT-DC/RT-FDC & $\begin{array}{l}\text { Combination of flow- } \\
\text { cytometry principles with } \\
\text { cell mechano-phenotyping in } \\
\text { response to hydrodynamic } \\
\text { shear stress. }\end{array}$ & $\begin{array}{l}\text { To evaluate single-platelet } \\
\text { deformability, stiffness, and } \\
\text { additional quantitative } \\
\text { parameters related to plate- } \\
\text { let morphometrics }\end{array}$ & $\begin{array}{l}\text { - Label-free } \\
\text { - High throughput } \\
\text { - High resolution } \\
\text { - Platelets analysis in } \\
\text { whole blood without } \\
\text { prior separation } \\
\text { - Commercially available }\end{array}$ & $\begin{array}{l}\text { - Limited to cells in } \\
\text { suspension }\end{array}$ \\
\hline
\end{tabular}

Abbreviations: AFM, atomic force microscopy; SICM, scanning ion conductance microscopy. 
demonstrated by AFM. Single-platelet elasticity module and areas at higher (e.g., edges) and lower (i.e., granulomere) stiffness upon platelet adhesion have been established. ${ }^{56}$ In addition, diverse adhesion forces produced by platelets adhering to different substrates (e.g., type 1 collagen, other platelets) according to their level of activation have been measured. ${ }^{57}$

Currently, our laboratory is using a modified version of AFM called colloidal probe spectroscopy combined with confocal laser scanning microscopy. We have implemented this approach to investigate the biomechanical properties such as stiffness in addition to activation status of platelet aggregates generated under shear on different adhesive matrices (-Fig. 3). Although colloidal probe spectroscopy is similar to AFM in its basic functionality, instead of a sharp tip at the terminal end of the cantilever a micrometer-sized bead is immobilized ( - Fig. 3A). In a typical colloidal probe experiment, the tip of the colloidal probe (i.e., microbead) is pushed gently against platelet aggregates by applying force in the order of a few nano newtons perpendicular to the horizontal plane of the platelet aggregate ( - Fig. $3 \mathrm{~B}$ ). This results in deflection of the cantilever, which is representative of the resistive force of the platelet aggregates. This approach enables us to systematically characterize biomechanical properties of platelet aggregates formed on a wide array of adhesive matrixes, under different shear-stress conditions emulating vascular flow dynamics, its microenvironment, and local architecture (-Fig. 3C-E). Specifically, the contribution of nano-/microstructure of the exposed ECM and geometrical constraints affecting hemodynamics such as stenosis and blood vessel bifurcations on biomechanical properties of platelet aggregates can be assessed by this technique. We envision this approach will also be suitable for the assessment of effects of antiplatelet drugs, fibrinolytic and antifibrinolytic drugs on platelet function offering a mechanistic insight into biophysical parameters involved in these processes.

\section{Scanning Ion Conductance Microscopy}

As a complimentary approach to AFM, SICM represents a noninvasive, label-free high-resolution methodology for biomechanical measurements. SICM analyzes the sample by detecting ionic current perturbation induced by the characteristics of the specimen in response to hydrostatic pressure application. ${ }^{58,59}$ With this tool, relevant insights into elasticity variation occurring during platelet spreading have been investigated. ${ }^{60}$ Moreover, the relationship between cytoskeleton remodeling and platelet stiffness upon thrombin-mediated platelet activation, or inhibition of actin polymerization, has been elucidated. ${ }^{61}$

\section{Real-Time Deformability Cytometry}

Most of the above-described biophysical methods used for biomechanical characterization of platelets are technically demanding and offer low throughput. ${ }^{62}$ To specifically address these issues, our laboratory has adopted a relatively easy-to-perform new technology called real-time deformability cytometry (RT-DC). ${ }^{63}$ RT-DC combines the technique of flow cytometry with label-free mechano-phenotyping (i.e., stiffness contributed by cytoskeleton) of cells using microfluidic laboratory-on-chip that is capable of reaching very high throughput of $>1,000$ single cells/second. In addition to determination of cell stiffness, RT-DC provides additional quantitative aspects related to cell size and morphometric parameters. This facilitates typifying a mixture of cells from peripheral blood by their size and simultaneously mechano-phenotyping these cells without prior separation, enrichment, and labeling procedures. ${ }^{64,65}$ To assess the effect of platelet cytoskeletal defects, recently Scheller et al using RT-DC have elegantly shown that platelets from mice lacking Coactosin-like 1 (Cotl1) actin-binding protein were biomechanically softer and smaller in size in comparison to their wild-type counterparts. ${ }^{45}$ In a latest technical development that is termed real-time 1D-imaging fluorescence and deformability cytometry (RT-FDC), it is possible to combine RT-DC measurements with fluorescence detection. ${ }^{66}$ We have applied RT-FDC to assess platelet cytoskeletal-dependent biomechanical and size characteristics combined with the platelet activation marker CD62P (P-selectin) ( - Fig. 4A, B). Using RT-FDC, we observed platelets upon stimulation with thrombin receptor activator peptide 6 (TRAP-6) become stiffer, undergo size reduction, and show CD62P expression. Surprisingly, platelets treated with cytochalasin $\mathrm{D}$ to block actin polymerization remained softer without undergoing significant size reduction while showing CD62P expression (-Fig. 4C, D).

Cytoskeleton Alterations in Inherited Platelet Disorders Inherited platelet disorders (IPDs) are a group of rare diseases characterized by reduced platelet count and/or impaired platelet function causing variable bleeding tendency and, sometimes, other nonhematological findings that can be congenital or acquired ${ }^{67}$ In regard to pathogenesis, most of the authors have categorized IPDs according to the impaired phase of platelet biogenesis, namely MK differentiation, MK maturation, or platelet formation. ${ }^{68,69}$ The latter, which consists of proplatelet elongation by MKs and release of mature platelets in the flowing blood, can be peculiarly affected by mutations occurring specifically in cytoskeleton proteins or integrins involved in the connection of cytoskeleton and platelet membrane. The implication of cytoskeleton in the pathogenesis of IPDs has been more comprehensively addressed by some other dedicated reviews over the last few years. ${ }^{70-72}$

In MYH9-related thrombocytopenia (MYH9-RD), one of the less rare forms of IPD, mutations affecting nonmuscular myosin IIA impair proplatelet formation leading to a delivery of a low number of enlarged platelets. In normal conditions, the interaction between MKs and bone-marrow ECM regulates the timing of platelet formation. Particularly, the binding of MKs with type 1 collagen, via $\alpha 2 \beta 1$ integrin, leads to activation of Rho kinase ROCK that phosphorylates the regulatory chains of nonmuscular myosin IIA, thus preventing platelet release as long as MKs have reached the vascular niche of the bone marrow. In fact, MYH9-RD MKs also display premature and ectopic platelet release. ${ }^{73-75}$ The mutated 
A

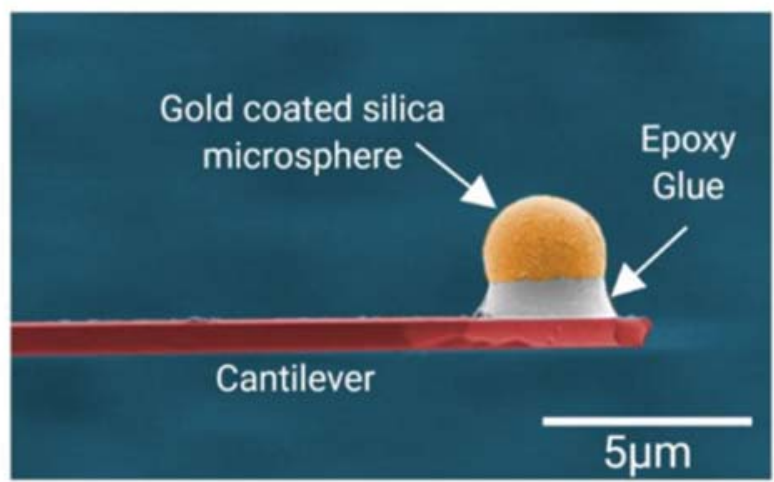

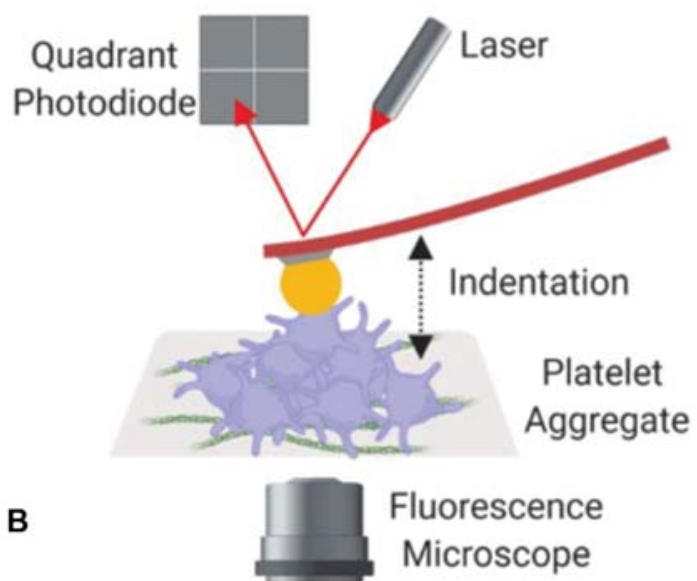

Transmission Mode

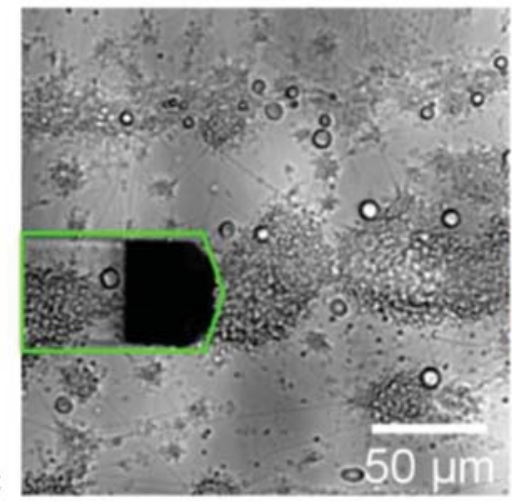

CD62P Fluorescene

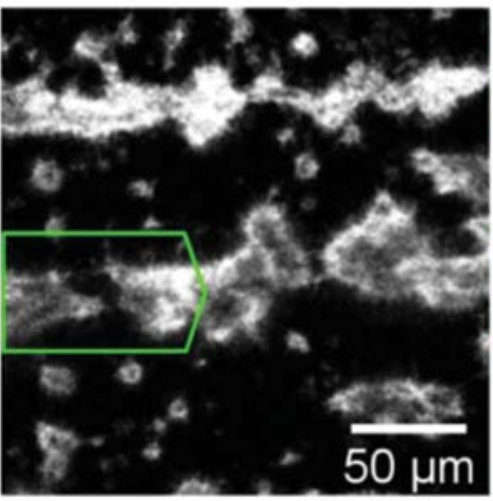

Overlay

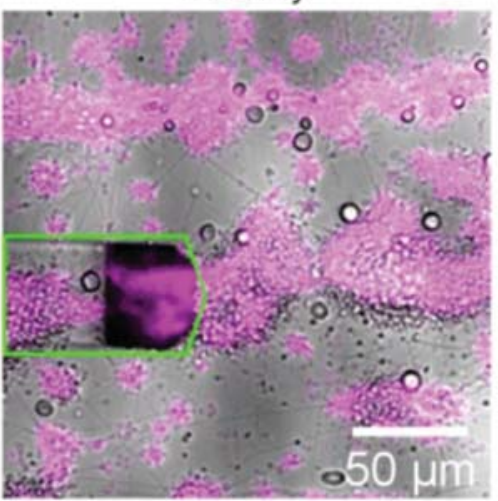

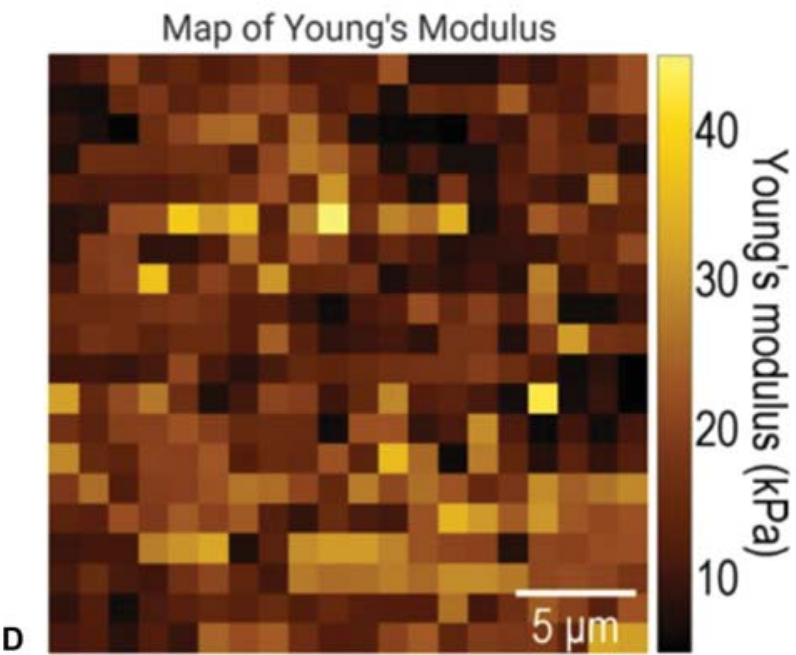

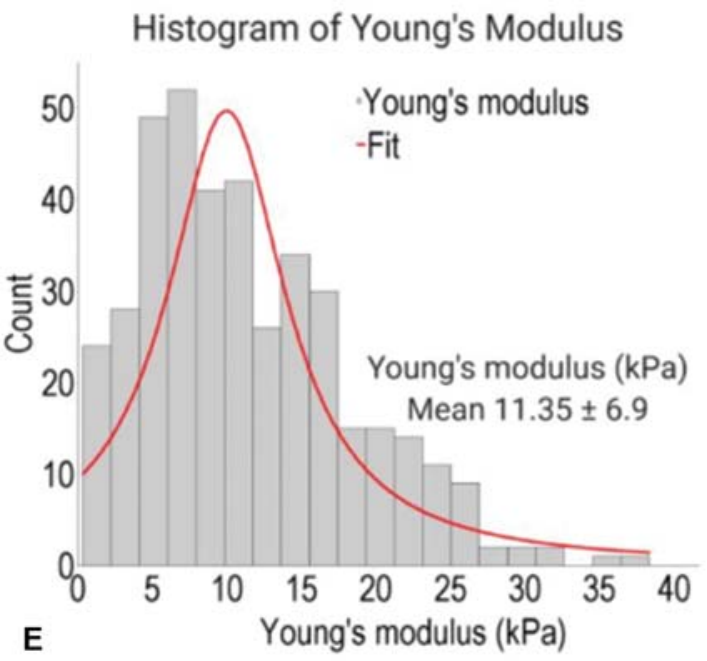

Fig. 3 Colloidal probe spectroscopy for biomechanical assessment of platelet aggregates. (A) Pseudocolored scanning electron micrograph of silicon nitride cantilever with a gold-coated microbead glued at its terminalend used for colloidal probe spectroscopy. (B) Similar to AFM, colloidal probe spectroscopy combines a sensitive octapoled piezoelectric transducer for $x$ - $y$ scanning, and an optical lever detection system for the analysis of the third dimension (the z-axis correlates to height movement in the piezo). The cantilever deflection is registered onto a quadrant photodiode from the reflected laser beam that provides a quantitative signal for the applied force as the colloidal probe is pushed against platelet aggregates, resulting in deflection of the cantilever according to the resistive force, $F$. According to this signal, $F$ can be calculated based on the Hooke's law $F=-k \cdot d$, where $k$ is the calibrated spring constant of the cantilever. (C) Different imaging modalities in an experimental setup using a combination of AFM and confocal laser scanning confocal microscopy. This allows identifying aggregates based on transmission, the fluorescence signal from activation status of platelets based on CD62P expression, and an overlay of the channels, allowing for an additional layer of useful information in combination with colloidal force spectroscopy. The green outline represents the cantilever above platelet aggregates formed under shear flow on a collagen substrate. (D) Representative 2D map of a platelet aggregate assessed by colloidal probe spectroscopy showing the map of Young's modulus ( $\mathrm{kPa}$ ) (i.e., biomechanical properties representing stiffness variations, see the look-up table on right) and (E) its distribution as a histogram. AFM, atomic force microscopy. 


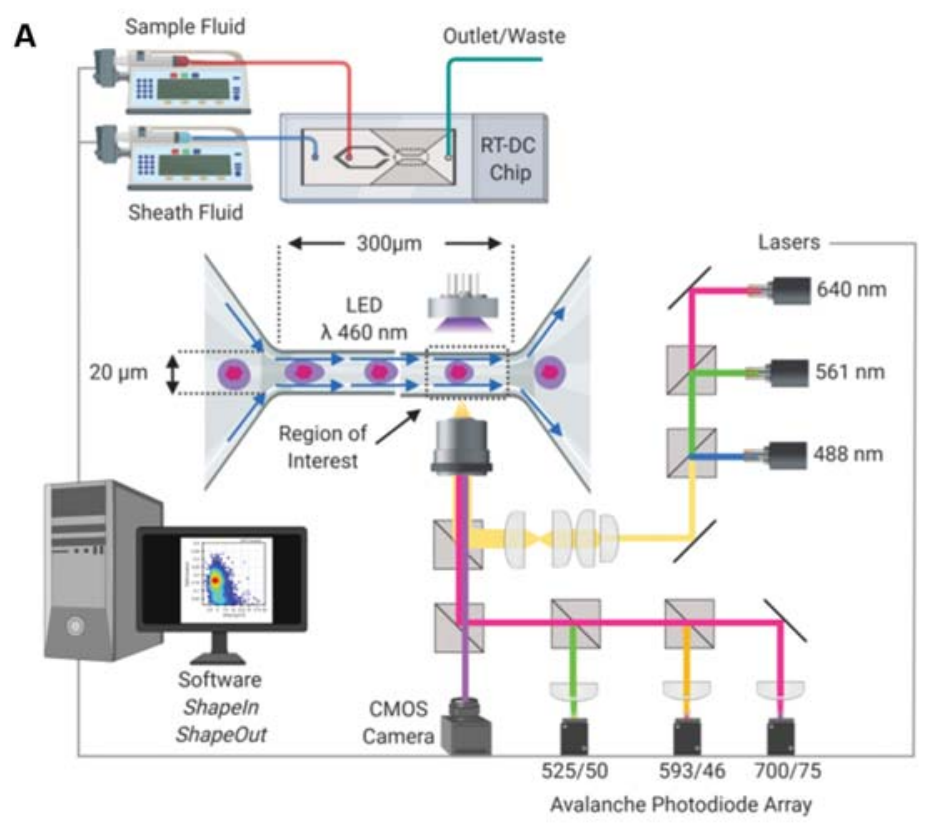

C
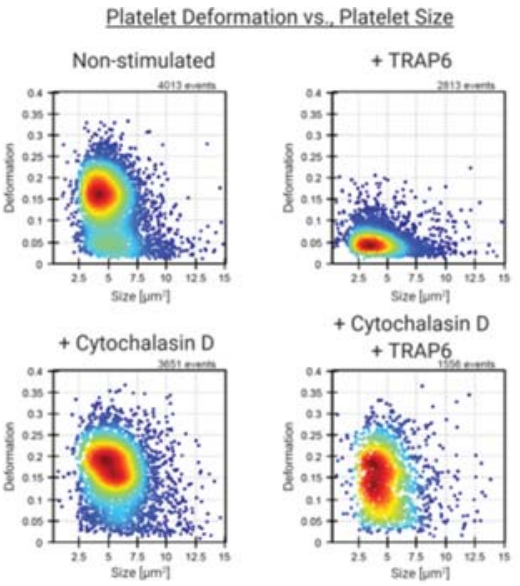

D Plat
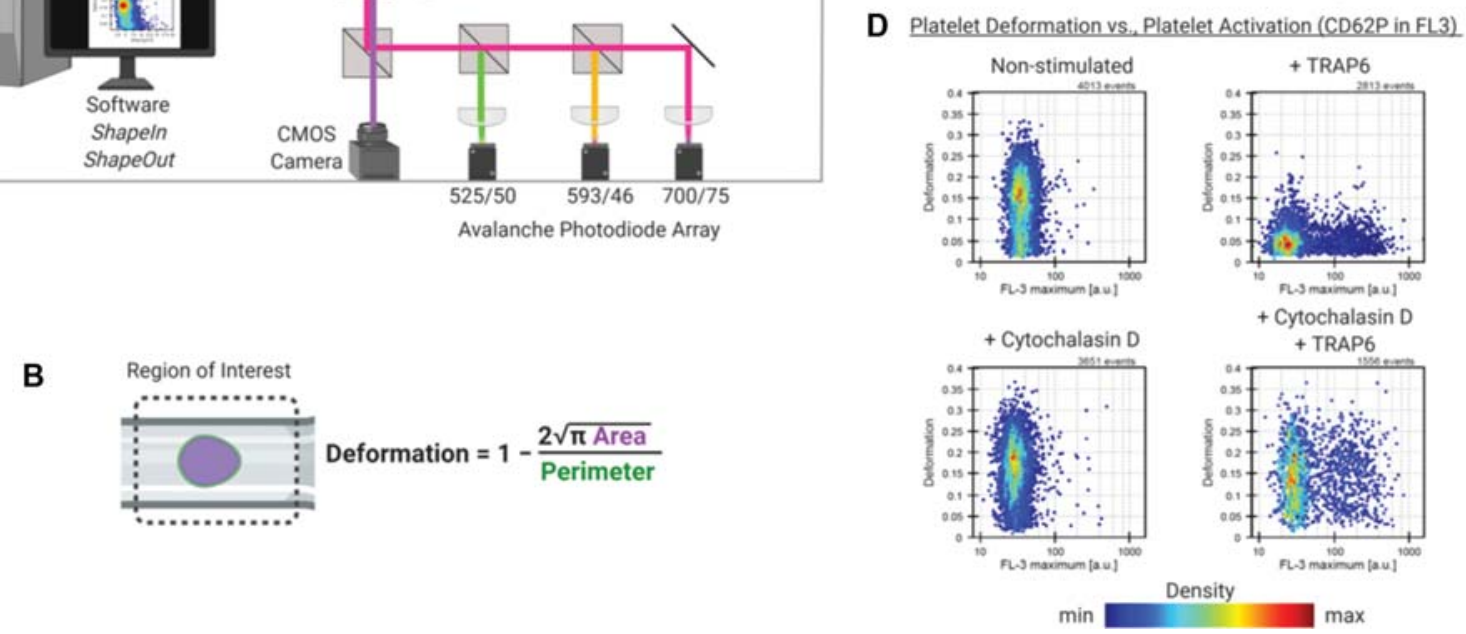

Fig. 4 Real-time 1D-imaging fluorescence and deformability cytometry (RT-FDC) as a biophysical tool for assessing single platelet biomechanics. (A) Schematic of RT-FDC setup showing a microfluidic chip connected to flow units with dedicated inlets for sheath fluid and for cells/platelets, which combine into to a channel with narrow constriction zone where cell/platelets undergo deformation as a result of hydrodynamic compression brought about by sheath fluid. A high-powered light emitting diode (LED) illuminates platelets flowing through the narrow constriction zone. Images are registered by a scientific complementary metal-oxide-semiconductor (sCMOS) camera working at high frame rates $(\approx 2,000$ images $/ \mathrm{s})$ that is synchronized with the frequency of illumination time. This combined together with dedicated optical setup, excitation lasers of different wave lengths, and avalanche photodiodes for fluorescence detection working in sync with camera allows for simultaneous mechano-phenotyping and detection of activation markers of $>1,000$ platelets per second. (B) Platelet deformation (i.e., cytoskeleton-dependent biomechanical properties governing stiffness) is determined on the fly in real time by computational image processing algorithm that takes into account the area and perimeter of the deformed platelet as it passes through the region of interest. (C, D) Representative results of a typical RT-FDC measurement showing unstimulated platelets deform more (i.e., softer) while those treated with agonist (TRAP-6) deform less (i.e., stiffer) while expressing activation marker CD62P. Whereas, platelets preincubated with cytochalasin D lead to increased deformation (i.e., softer) and in combination with TRAP-6 co-stimulation platelets remain softer while still being able to undergo activation. Data show density maps of deformation against area $\left(\mu \mathrm{m}^{2}\right)$ from $n \geq 1,500$ individual platelets from a single experiment.

nonmuscular myosin IIA forms aggregates of diverse number and dimension in the cytoplasm of neutrophils, which is already used as diagnostic criterion. ${ }^{76}$

Wiskott-Aldrich syndrome (WAS) and X-linked thrombocytopenia, two IPDs featured by thrombocytopenia and mild-to-severe immunodeficiency, are caused by alterations in the WAS gene. The corresponding protein WAS regulates actin cytoskeleton. Even in this case, patients' MKs show ectopic release of platelets, which also present a small size and a reduced life span. ${ }^{77,78}$ The $\beta 1$ tubulin rings in WAS are much more rigid and stretched-or present in eight-shaped conformations. $^{79}$

Two others IPDs due to alterations in cytoskeletal components are ACTN1-related thrombocytopenia (ACTN1-RT) and FLNA-related thrombocytopenia (FLNA-RT). ${ }^{80,81}$ The mutat- ed proteins $\alpha 1$ actinin and filamin A, respectively, interact with actin and take part in diverse functions of cytoskeleton as the maintenance of stability properties and anchoring to the membrane. While no typical morphological changes for ACTN1-RT have been identified, in FLNA-RT, affected subjects can be detected by double labeling against filamin $A$ and $\beta 1$ tubulin; the former protein can be undetectable at all or, sometimes, show diffused distribution instead of a thick peripheral ring. ${ }^{81}$

Mutations in another key element of microtubule architecture, $\beta 1$ tubulin, cause TUBB1-related thrombocytopenia (TUBB1-RT). Also in this form, features of impaired proplatelet processing and platelet shedding have been reported. ${ }^{82}$ In TUBB1-RT $\beta 1$ tubulin, normally forming a peripheral ring structure, is disturbed. ${ }^{83}$ These patients display enlarged 


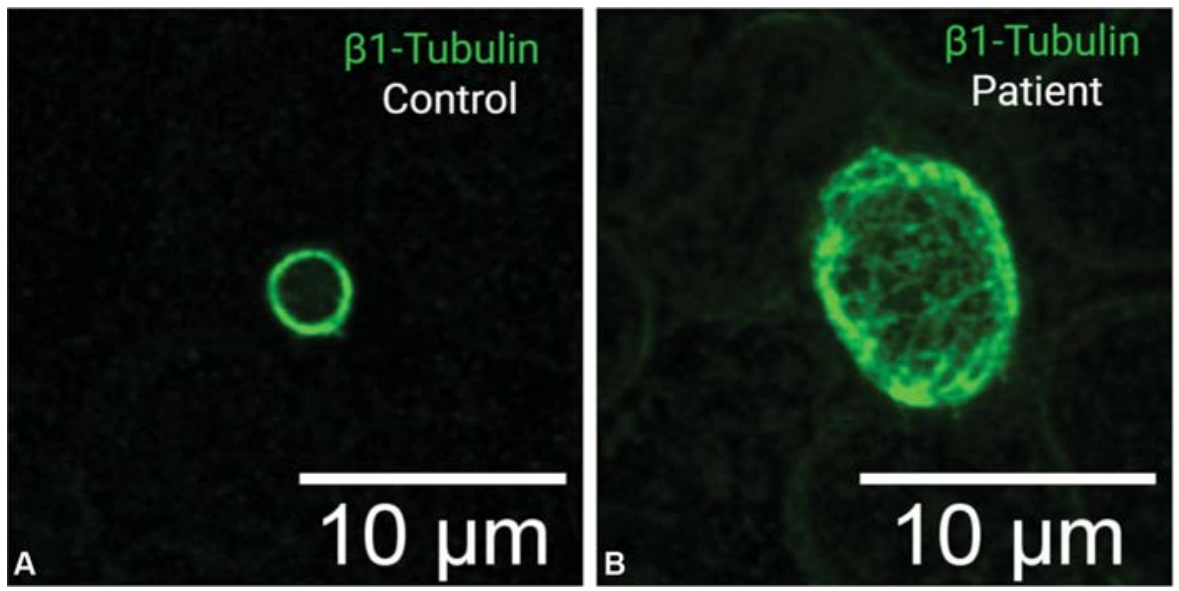

Fig. 5 Identification of TUBB1-related thrombocytopenia on a blood smear. (A) Marginal band B1 tubulin in healthy control. (B) A "ball of yarn"-like distribution in a patient carrying a causative mutation in the TUBB1 gene observed by confocal laser scanning immunofluorescence microscopy.

platelets in which $\beta 1$ tubulin resembles the appearance of a ball of yarn (-Fig. 5). Finally, in macro-thrombocytopenia due to a gain-of-function variant in DIAPH1, $\alpha$-tubulin rings are also much more rigid and maintain their ring form when the blood is cooled down to $4^{\circ} \mathrm{C}$, a condition under which normally microtubules disassemble. ${ }^{77}$

Beyond binding to their specific extracellular ligands (e.g., von Willebrand Factor and fibrinogen), platelet receptor complex GP Ib-IX-V and integrin GP IIb/IIIa also stabilize the interaction between cytoskeleton and membrane. Alterations of this dynamic equilibrium can perturb proplatelet formation leading to ectopic and inefficient platelet production. ${ }^{69}$ For instance, in regard to monoallelic BSS, the heterozygous c.515C > T transition in GPIBA gene (i.e., Bolzano mutation) drives a dominant form of macro-thrombocytopenia with defective proplatelet formation because of impaired crosstalking between plasma membrane and platelet cytoskeleton via the intracellular chain of GPIbo. ${ }^{84}$ Conversely, gain-offunction mutations in ITGA2B or ITGB3 (coding GPIIb and GPIIIa) cause a dominant variant of Glanzmann thrombasthenia with mild thrombocytopenia, large platelets, and constitutive activation of GP IIb/IIIa. ${ }^{85}$ The impaired function of this integrin specifically triggers cytoskeleton remodeling and, in turn, alterations in the latest phase of platelet biogenesis.

Although the role of cytoskeleton has been largely elucidated in normal megakaryopoiesis and in the pathogenesis of some IPDs, much less is known about the possible impact of the reported cytoskeletal alterations on the biomechanical properties of platelets. Understanding the associated alterations of biomechanical consequences in IPDs represents an unmet need. It might be that changes in the biomechanical properties caused by IPDs could explain, for example, the variability of hemorrhagic diathesis observed in patients sharing similar levels of platelet counts and functional parameters as assessed by traditional tools. Moreover, since cytoskeletal elements represent possible pharmaceutical targets, unraveling biomechanical alteration of single or group of IPDs can lay the ground for the development of new therapeutic options to prevent and contrast bleeding symptoms in these patients. ${ }^{67,86}$

\section{Time Capsule}

\section{Key Advantages to Be Expected in 2050}

- Super-resolution immunofluorescence microscopy will enable visualization of finer details of platelet cytoskeletal defects below diffraction limits, thus allowing a nanoscopic and mechanistic view of platelet function.

- Wider application of biophysical methods such as AFM and RT-DC will broaden our knowledge about underlying biomechanical principles affecting platelet cytoskeleton and their impact on platelet function.

- In the field of IPDs, the implementation of biomechanical investigations is anticipated to clarify pathogenic mechanisms of a relevant group of disorders, and to pave the way for a major role in diagnostic work-up and management.

- From a clinical point of view, the use of biomechanical assessment as point-of-care testing is expected to represent a key modality to stratify patients for bleeding (and thrombotic) risk, thus allowing tailored therapy and monitoring approaches. RT-DC, for the first time, allows such an approach with a high enough throughput suitable to clinical needs.

\section{Contributions}

CZ, LS and RP wrote the paper. LS and RP performed CLSM, SEM, AFM and RT-DC experiments, analyzed and interpretaed the data and prepared figures.

Conflict of Interest

The authors declare that they have no conflict of interest.

\section{Acknowledgments}

The authors thank Dr. Oliver Otto, Group Leader Biomechanics, Center for Innovation Competence at University of Greifswald, Germany, for providing access to RT-DC instrumentation and facilities. The authors thank Dr. Andreas Greinacher, Department of Transfusion Medicine, University Medicine Greifswald, Germany, for providing access to immunofluorescence preparations of patient blood smears. Schematic representations were 
created using BioRender. L.S. is funded by the Deutsche Forschungsgemeinschaft (DFG, German Research foundation) Project Number 374031971-TRR 240, Project A06 granted to R.P.

\section{Authors}

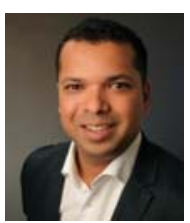

\section{Raghavendra Palankar}

Institute of Immunology and Transfusion Medicine

University Medicine Greifswald

17489, Greifswald, Germany.

Raghavendra Palankar, PhD, obtained his $\mathrm{PhD}$ in Biochemical Engineering (with special distinction) in the year 2010 from Jacobs University Bremen, Germany. His doctoral work focused on development of optically addressable polymer and nanoparticle composites for precision intracellular drug delivery and sensing applications. During his doctoral studies, he was a visiting researcher at Max Planck Institute of Colloids and Interfaces, Potsdam, Germany, and at Swiss Federal Institute of Technology (EPFL) in Lausanne, Switzerland, through Marie Curie Actions Research Training Networks (RTN). Between 2010 and 2011, Dr. Palankar conducted postdoctoral research at Max Planck Institute for Biophysical Chemistry, Göttingen, Germany, on single receptor manipulation and fluorescence imaging in the Laboratory of Cellular Dynamics under the guidance of Dr. Thomas Jovin. In 2012, he joined Center for Innovation Competence to develop Nano-technological and Biophysical tools for platelet research. Since July 2018, Dr. Palankar is a principal investigator in German Research Foundation (DFG) funded collaborative research center SFB TR240. Current research in the laboratory focuses on role of platelet cytoskeleton on platelet function and platelet-pathogen interactions.

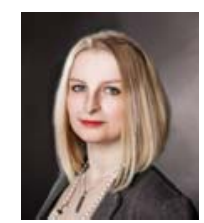

\section{Laura Sachs}

Institute of Immunology and Transfusion Medicine

University Medicine Greifswald

17489, Greifswald, Germany.

Laura Sachs, Dipl.-Pharm., graduated in pharmacy from the University of Greifswald in 2018. As a part of her diploma thesis at the Center for Innovation Competence-Humoral Immune Reactions in Cardiovascular Diseases (ZIK-HIKE Greifswald), Laura Sachs performed research on high-throughput mechano-phenotyping of cryopreserved peripheral blood cells. Since 2019, she has been working on her doctoral thesis in the collaborative research center SFB TR240, funded by the German Research Foundation (DFG), in the Department of Transfusion Medicine, University Medicine Greifswald. Her research work focuses on the role of platelet cytoskeleton in platelet function from a biomechanical perspective under the guidance of Dr. Palankar.

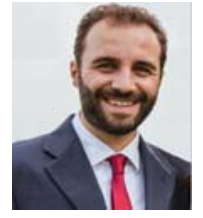

\section{Carlo Zaninetti}

Institute of Immunology and Transfusion Medicine

University Medicine Greifswald

Carlo Zaninetti was born in Domodossola (Italy) in 1985. He graduated in Medicine and Surgery in 2011 at the University of Pavia, one of the cradles of hematology. He performed his clinical and research training at the Department of Internal Medicine of the University Hospital IRCCS Policlinico San Matteo Foundation, Pavia, as a disciple of the hematologists Rosangela Invernizzi and Carlo L. Balduini. During his PhD course, he prevalently focused on clinical and biologic aspects of inherited platelet disorders. Recently, he moved to Germany to pursue his studies on platelet physiopathology under the mentorship of Professor Andreas Greinacher at the Department of Transfusion Medicine, University Medicine of Greifswald.

\section{References}

1 Wickstead B, Gull K. The evolution of the cytoskeleton. J Cell Biol 2011;194(04):513-525

2 Fletcher DA, Mullins RD. Cell mechanics and the cytoskeleton. Nature 2010;463(7280):485-492

3 Flitney EW, Kuczmarski ER, Adam SA, Goldman RD. Insights into the mechanical properties of epithelial cells: the effects of shear stress on the assembly and remodeling of keratin intermediate filaments. FASEB J 2009;23(07):2110-2119

4 Harris AR, Jreij P, Fletcher DA. Mechanotransduction by the actin cytoskeleton: converting mechanical stimuli into biochemical signals. Annu Rev Biophys 2018;47:617-631

5 Klingler-Hoffmann M, Mittal P, Hoffmann P. The emerging role of cytoskeletal proteins as reliable biomarkers. Proteomics 2019;19 (21-22):e1800483

6 Guck J. Some thoughts on the future of cell mechanics. Biophys Rev 2019;11(05):667-670

7 Giganti A, Friederich E. The actin cytoskeleton as a therapeutic target: state of the art and future directions. Prog Cell Cycle Res 2003;5:511-525

8 Van Vuren A, van der Zwaag B, Huisjes R, et al. The complexity of genotype-phenotype correlations in hereditary spherocytosis: a cohort of 95 patients. Hemasphere 2019;3:e276. https://pubmed. ncbi.nlm.nih.gov/31723846/

9 Tesson F, Saj M, Uvaize MM, Nicolas H, Płoski R, Bilińska Z. Lamin A/C mutations in dilated cardiomyopathy. Cardiol J 2014;21(04): 331-342

$10 \mathrm{Fu} \mathrm{Y}$, Eisen HJ. Genetics of dilated cardiomyopathy. CurrCardiol Rep 2018;20(11):121

11 Machlus KR, Italiano JE Jr. The incredible journey: from megakaryocyte development to platelet formation. J Cell Biol 2013;201 (06):785-796

12 Thon JN, Montalvo A, Patel-Hett S, et al. Cytoskeletal mechanics of proplatelet maturation and platelet release. J Cell Biol 2010;191 (04):861-874

13 Bender M, Stritt S, Nurden P, et al. Megakaryocyte-specific profilin1-deficiency alters microtubule stability and causes a Wiskott-Aldrich syndrome-like platelet defect. Nat Commun 2014;5:4746

14 Feghhi S, Munday AD, Tooley WW, et al. Glycoprotein Ib-IX-V complex transmits cytoskeletal forces that enhance platelet adhesion. Biophys J 2016;111(03):601-608

15 Sanjuan-Pla A, Macaulay IC, Jensen CT, et al. Platelet-biased stem cells reside at the apex of the haematopoietic stem-cell hierarchy. Nature 2013;502(7470):232-236 
16 Italiano JE Jr, Lecine P, Shivdasani RA, Hartwig JH. Blood platelets are assembled principally at the ends of proplatelet processes produced by differentiated megakaryocytes. J Cell Biol 1999;147 (06):1299-1312

17 Schwertz H, Köster S, Kahr WHA, et al. Anucleate platelets generate progeny. Blood 2010;115(18):3801-3809

18 Richardson JL, Shivdasani RA, Boers C, Hartwig JH, Italiano JE Jr. Mechanisms of organelle transport and capture along proplatelets during platelet production. Blood 2005;106(13):4066-4075

19 Thon JN, Macleod H, Begonja AJ, et al. Microtubule and cortical forces determine platelet size during vascular platelet production. Nat Commun 2012;3:852

20 Gieger C, Radhakrishnan A, Cvejic A, et al. New gene functions in megakaryopoiesis and platelet formation. Nature 2011;480 (7376):201-208

21 Weyrich AS, Zimmerman GA. Platelets: signaling cells in the immune continuum. Trends Immunol 2004;25(09):489-495

22 Gay LJ, Felding-Habermann B. Contribution of platelets to tumour metastasis. Nat Rev Cancer 2011;11(02):123-134

23 Gaertner F, Massberg S. Patrolling the vascular borders: platelets in immunity to infection and cancer. Nat Rev Immunol 2019;19 (12):747-760

24 Franco AT, Corken A, Ware J. Platelets at the interface of thrombosis, inflammation, and cancer. Blood 2015;126(05):582-588

25 Palankar R, Kohler TP, Krauel K, Wesche J, Hammerschmidt S, Greinacher A. Platelets kill bacteria by bridging innate and adaptive immunity via platelet factor 4 and FcrRIIA. J ThrombHaemost 2018;16(06):1187-1197

26 Wolff M, Handtke S, Palankar R, et al. Activated platelets kill Staphylococcus aureus, but not Streptococcus pneumoniae-the role of FcrRIIa and platelet factor 4/heparinantibodies. J ThrombHaemost 2020;18:1459-1468. https://doi.org/10.1111/jth.14814

27 Sorrentino S, Studt J-D, Medalia O, TanujSapra K. Roll, adhere, spread and contract: structural mechanics of platelet function. Eur J Cell Biol 2015;94(3-4):129-138

28 White JG, Rao GH. Microtubule coils versus the surface membrane cytoskeleton in maintenance and restoration of platelet discoid shape. Am J Pathol 1998;152(02):597-609

29 Springer TA, Dustin ML. Integrin inside-out signaling and the immunological synapse. CurrOpin Cell Biol 2012;24(01):107-115

30 Tadokoro S, Shattil SJ, Eto K, et al. Talin binding to integrin $\beta$ tails: a final common step in integrin activation. Science 2003;302(5642): 103-106

31 Liu S, Calderwood DA, Ginsberg MH. Integrin cytoplasmic domain-binding proteins. J Cell Sci 2000;113(Pt 20):3563-3571

32 Bennett JS, Berger BW, Billings PC. The structure and function of platelet integrins. J ThrombHaemost 2009;7(Suppl 1):200-205

33 Lickert S, Sorrentino S, Studt J-D, Medalia O, Vogel V, Schoen I. Morphometric analysis of spread platelets identifies integrin $\alpha_{\text {IIb }} \beta_{3}$-specific contractile phenotype. Sci Rep 2018;8(01):5428

34 Ciciliano JC, Tran R, Sakurai Y, Lam WA. The platelet and the biophysical microenvironment: lessons from cellular mechanics. Thromb Res 2014;133(04):532-537

35 Italiano JE Jr, Bergmeier W, Tiwari S, et al. Mechanisms and implications of platelet discoid shape. Blood 2003;101(12): 4789-4796

36 Hartwig JH. Mechanisms of actin rearrangements mediating platelet activation. J Cell Biol 1992;118(06):1421-1442

37 Pollard TD, Borisy GG. Cellular motility driven by assembly and disassembly of actin filaments. Cell 2003;112(04):453-465

38 Calaminus SDJ, Auger JM, McCarty OJT, Wakelam MJ, Machesky LM, Watson SP. MyosinIla contractility is required for maintenance of platelet structure during spreading on collagen and contributes to thrombus stability. J ThrombHaemost 2007;5 (10):2136-2145

39 Feghhi S, Tooley WW, Sniadecki NJ. Nonmusclemyosin IIA regulates platelet contractile forces through Rho kinase and myosin lightchain kinase. J BiomechEng 2016;138(10):1045061-1045064
40 Johnson GJ, Leis LA, Krumwiede MD, White JG. The critical role of myosin IIA in platelet internal contraction. J ThrombHaemost 2007;5(07):1516-1529

41 Flaumenhaft R, Dilks JR, Rozenvayn N, Monahan-Earley RA, Feng D, Dvorak AM. The actin cytoskeleton differentially regulates platelet $\alpha$-granule and dense-granule secretion. Blood 2005; 105(10):3879-3887

42 Lam WA, Chaudhuri O, Crow A, et al. Mechanics and contraction dynamics of single platelets and implications for clot stiffening. Nat Mater 2011;10(01):61-66

43 Hansen CE, Qiu Y, McCarty OJT, Lam WA. Platelet mechanotransduction. Annu Rev Biomed Eng 2018;20:253-275

44 Oshinowo OT, Lam AW, Brainard B, et al. Platelet contraction cytometry: a biophysical, high-throughput research-enabling and diagnostic platform. Blood 2017;130:2301

45 Scheller I, Stritt S, Beck S, et al. Coactosin-like 1 integrates signaling critical for shear-dependent thrombus formation in mouse platelets. Haematologica 2020;105(06):1667-1676. DOI: 10.3324/haematol.2019.225516

46 Sachs L, Denker C, Greinacher A, Palankar R. Quantifying singleplatelet biomechanics: An outsider's guide to biophysical methods and recent advances. Res PractThrombHaemost 2020;4(03): 386-401

47 Lickert S, Selcuk K, Kenny M, et al. Platelets exploit fibrillar adhesions to assemble fibronectin matrix revealing new forceregulated thrombus remodeling mechanisms. bioRxiv 2020. Doi: 10.1101/2020.04.20.050708

48 Myers DR, Qiu Y, Fay ME, et al. Single-platelet nanomechanics measured by high-throughput cytometry. Nat Mater 2017;16 (02):230-235

49 Zhang Y, Qiu Y, Blanchard AT, et al. Platelet integrins exhibit anisotropic mechanosensing and harness piconewton forces to mediate platelet aggregation. Proc Natl Acad Sci U S A 2018;115 (02):325-330

50 González-Bermúdez B, Guinea GV, Plaza GR. Advances in micropipette aspiration: applications in cell biomechanics, models, and extended studies. Biophys J 2019;116(04):587-594

51 White JG, Burris SM, Tukey D, Smith C II, Clawson CC. Micropipette aspiration of human platelets: influence of microtubules and actin filaments on deformability. Blood 1984;64(01):210-214

52 White JG, Burris SM, Hasegawa D, Johnson M. Micropipette aspiration of human blood platelets: a defect in Bernard-Soulier's syndrome. Blood 1984;63(05):1249-1252

53 Burris SM, Smith CM II, Rao GH, White JG. Aspirin treatment reduces platelet resistance to deformation. Arteriosclerosis 1987; 7(04):385-388

54 Burris SM, Smith CM II, Tukey DT, Clawson CC, White JG. Micropipette aspiration of human platelets after exposure to aggregating agents. Arteriosclerosis 1986;6(03):321-325

55 Ando T. Directly watching biomolecules in action by high-speed atomic force microscopy. Biophys Rev 2017;9(04):421-429

56 Radmacher M, Fritz M, Kacher CM, Cleveland JP, Hansma PK. Measuring the viscoelastic properties of human platelets with the atomic force microscope. Biophys J 1996;70(01):556-567

57 Nguyen TH, Palankar R, Bui VC, Medvedev N, Greinacher A, Delcea M. Rupture forces among human blood platelets at different degrees of activation. Sci Rep 2016;6:25402

58 Hansma PK, Drake B, Marti O, Gould SA, Prater CB. The scanning ion-conductance microscope. Science 1989;243(4891):641-643

59 Happel P, Thatenhorst D, Dietzel ID. Scanning ion conductance microscopy for studying biological samples. Sensors (Basel) 2012; 12(11):14983-15008

60 Rheinlaender J, Vogel S, Seifert J, et al. Imaging the elastic modulus of human platelets during thrombin-induced activation using scanning ion conductance microscopy. ThrombHaemost 2015; 113(02):305-311

61 Seifert J, Rheinlaender J, Lang F, Gawaz M, Schäffer TE. Thrombininduced cytoskeleton dynamics in spread human platelets 
observed with fast scanning ion conductance microscopy. Sci Rep 2017;7(01):4810

62 Sachs L, Denker C, Greinacher A, Palankar R. Quantifying single platelet biomechanics: an outsider's guide to biophysical methods and recent advances. Res Pract Thromb Haemost 2020;4(03): 386-401. https://doi.org/10.1002/rth2.12313

63 Otto O, Rosendahl P, Mietke A, et al. Real-time deformability cytometry: on-the-fly cell mechanical phenotyping. Nat Methods 2015;12(03):199-202, 4, 202

64 Mietke A, Otto O, Girardo S, et al. Extracting cell stiffness from real-time deformability cytometry: theory and experiment. Biophys J 2015;109(10):2023-2036

65 Toepfner N, Herold C, Otto O, et al. Detection of human disease conditions by single-cell morpho-rheological phenotyping of blood. eLife 2018;7:e29213

66 Rosendahl P, Plak K, Jacobi A, et al. Real-time fluorescence and deformability cytometry. Nat Methods 2018;15(05):355-358

67 Noris P, Pecci A. Hereditary thrombocytopenias: a growing list of disorders. Hematology (Am Soc Hematol Educ Program) 2017; 2017(01):385-399

68 Balduini CL, Melazzini F, Pecci A. Inherited thrombocytopeniasrecent advances in clinical and molecular aspects. Platelets 2017; 28(01):3-13

69 Pecci A, Balduini CL. Lessons in platelet production from inherited thrombocytopenias. Br J Haematol 2014;165(02):179-192

70 Balduini A, Raslova H, Di Buduo CA, et al. Clinic, pathogenic mechanisms and drug testing of two inherited thrombocytopenias, ANKRD26-related thrombocytopenia and MYH9-related diseases. Eur J Med Genet 2018;61(11):715-722

71 Johnson B, Fletcher SJ, Morgan NV. Inherited thrombocytopenia: novel insights into megakaryocyte maturation, proplatelet formation and platelet lifespan. Platelets 2016;27(06):519-525

72 Pecci A. Pathogenesis and management of inherited thrombocytopenias: rationale for the use of thrombopoietin-receptor agonists. Int J Hematol 2013;98(01):34-47

73 Seri M, Pecci A, Di Bari F, et al. MYH9-related disease: MayHegglin anomaly, Sebastian syndrome, Fechtner syndrome, and Epstein syndrome are not distinct entities but represent a variable expression of a single illness. Medicine (Baltimore) 2003;82 (03):203-215

74 Chen Z, Naveiras O, Balduini A, et al. The May-Hegglin anomaly gene MYH9 is a negative regulator of platelet biogenesis modulated by the Rho-ROCK pathway. Blood 2007;110(01):171-179
75 Pecci A, Malara A, Badalucco S, et al. Megakaryocytes of patients with MYH9-related thrombocytopenia present an altered proplatelet formation. ThrombHaemost 2009;102(01): 90-96

76 Savoia A, De Rocco D, Panza E, et al. Heavy chain myosin 9-related disease (MYH9 -RD): neutrophil inclusions of myosin-9 as a pathognomonic sign of the disorder. ThrombHaemost 2010;103 (04):826-832

77 Massaad MJ, Ramesh N, Geha RS. Wiskott-Aldrich syndrome: a comprehensive review. Ann N Y Acad Sci 2013;1285:26-43

78 Sabri S, Foudi A, Boukour S, et al. Deficiency in the Wiskott-Aldrich protein induces premature proplatelet formation and platelet production in the bone marrow compartment. Blood 2006;108 (01):134-140

79 Greinacher A, Pecci A, Kunishima S, et al. Diagnosis of inherited platelet disorders on a blood smear: a tool to facilitate worldwide diagnosis of platelet disorders. J ThrombHaemost 2017;15(07): 1511-1521

80 Kunishima S, Okuno Y, Yoshida K, et al. ACTN1 mutations cause congenital macrothrombocytopenia. Am J Hum Genet 2013;92 (03):431-438

81 Nurden P, Debili N, Coupry I, et al. Thrombocytopenia resulting from mutations in filamin A can be expressed as an isolated syndrome. Blood 2011;118(22):5928-5937

82 Kunishima S, Kobayashi R, Itoh TJ, Hamaguchi M, Saito H. Mutation of the $\beta 1$-tubulin gene associated with congenital macrothrombocytopenia affecting microtubule assembly. Blood 2009; 113(02):458-461

83 Kunishima S, Nishimura S, Suzuki H, Imaizumi M, Saito H. TUBB1 mutation disrupting microtubule assembly impairs proplatelet formation and results in congenital macrothrombocytopenia. Eur J Haematol 2014;92(04):276-282

84 Balduini A, Malara A, Pecci A, et al. Proplatelet formation in heterozygous Bernard-Soulier syndrome type Bolzano. J ThrombHaemost 2009;7(03):478-484

85 Bury L, Falcinelli E, Chiasserini D, Springer TA, Italiano JE Jr, Gresele P. Cytoskeletal perturbation leads to platelet dysfunction and thrombocytopenia in variant forms of Glanzmann thrombasthenia. Haematologica 2016;101(01):46-56

86 Gresele P, Orsini S, Noris P, et al. Validation of the ISTH/SSC bleeding assessment tool for inherited platelet disorders: a communication from the Platelet Physiology SSC. J ThrombHaemost 2020;18(03):732-739 